\title{
BMJ Open Abductor muscle strength deficit in patients after total hip arthroplasty for hip osteoarthritis: a protocol for a systematic review and meta-analysis
}

\author{
Petros Ismailidis (D) ,1,2 Peter Kvarda (D) , ${ }^{1,3}$ Werner Vach, ${ }^{1}$ \\ Christian Appenzeller-Herzog (D) , ${ }^{4}$ Annegret Mündermann ${ }^{1,2,5}$
}

To cite: Ismailidis $\mathrm{P}$, Kvarda $\mathrm{P}$, Vach W, et al. Abductor muscle strength deficit in patients after total hip arthroplasty for hip osteoarthritis: a protocol for a systematic review and meta-analysis. BMJ Open 2020;10:e035413. doi:10.1136/ bmjopen-2019-035413

- Prepublication history and additional material for this paper are available online. To view these files, please visit the journal online (http://dx.doi. org/10.1136/bmjopen-2019035413).

Received 30 October 2019 Revised 05 March 2020 Accepted 07 June 2020

Check for updates

(C) Author(s) (or their employer(s)) 2020. Re-use permitted under CC BY-NC. No commercial re-use. See rights and permissions. Published by BMJ.

For numbered affiliations see end of article.

Correspondence to Dr Petros Ismailidis; petrosismailidis@gmail.com

\section{ABSTRACT}

Introduction Conservation of abductor muscle strength is directly associated with physical function after total hip replacement (THA). Although many studies have tried to explore and quantify a potential abductor muscle strength deficit after THA as well as identify possible causes and treatment options, this topic has not been addressed systematically.

Methods and analysis Human-based studies reporting measurements of hip abductor strength will be included in this review. Studies reporting on hip abductor strength measured manually or isometric measurements at an abduction angle other than $0^{\circ}$ will not be considered. No restriction will be placed on study design, publication date operative approach, prosthesis design, age and sex of the patients or severity of OA. Data sources will be Embase via embase.com, Medline ALL via Ovid and the Cochrane Central Register of Controlled Trials. The preliminary search was conducted on 5 May 2019. Data regarding absolute values or torque ratio of hip abductor torque between sides as well as patient demographic data, surgical approaches and rehabilitation protocols will be extracted. The assessment of quality and risk of bias will be performed with the modified Newcastle-Ottawa Scale. The screening, data extraction and quality assessment will be performed by two reviewers independently. Where necessary, a third review author will make a final judgement. Narrative synthesis as well as tabular presentation of the extracted data will be included. Whenever possible, metaregression and subgroup specific meta-analyses will be used to investigate the influence of time since THA and type of measurement (isokinetic or isometric) on the different outcomes. In case of sufficient information, these analyses will be extended to include characteristics such as age, sex, surgical approach or rehabilitation programme.

Ethics and dissemination No ethics approval is required. The results will be disseminated through peer-reviewed publications and conference presentations. PROSPERO registration number CRD42020153185.

\section{INTRODUCTION}

Osteoarthritis (OA) of the hip is a common degenerative disorder. Despite its high prevalence, to date there is no cure for OA, and the ultimate treatment for severe OA is total
Strengths and limitations of this study

To the best of our knowledge, this will be the first systematic review examining if abductor muscle strength deficit is present in patients after total hip arthroplasty performed for osteoarthritis.

- The homogeneity of the measurement methods described in the inclusion criteria (no hand-held manometers, isometric measurements only in an abduction angle of $0^{\circ}$ ) allows the extraction of directly comparable data, suitable for a meta-analysis.

- This review will likely identify factors influencing the abductor strength deficit, hence assisting the choice of the correct surgical methods or rehabilitation protocols.

- A possible limitation is the inclusion of studies only in English or German language.

hip arthroplasty (THA). ${ }^{1}$ Overall, the results of THA appear to be very satisfying with more than $90 \%$ of THA patients reporting a good to excellent result. ${ }^{2}$ However, patients after THA have been reported to have strength deficits. ${ }^{3}$ These deficits have been described in patients with $\mathrm{OA}$ and reported to increase as the disease progresses and persist for a longer time after THA treatment. ${ }^{4}$ One of the most common strength deficits is that of the abductor muscle group. ${ }^{4}$ Abductor muscle group deficit after THA can be described compared with a control group of healthy individuals ${ }^{6}$ or comparing the affected hip with the contralateral side in case of unilateral THA. ${ }^{7}$

The abductor muscle group mainly consist of the primary hip abductors gluteus medius, gluteus minimus and tensor fasciae latae muscles. Secondary hip abductors include the piriformis, sartorius and rectus femoris muscles. ${ }^{8}$ The abductor muscle group abducts the hip and stabilises the pelvis, maintaining the level of contralateral pelvis 
and preventing hip adduction during single leg stance. ${ }^{910}$ Furthermore, the gluteus medius and minimus have a secondary role in hip rotation. ${ }^{8}$

Damage of the abductor mechanism results in drop of the contralateral pelvis during single leg stance clinically manifested as a Trendelenburg gait. ${ }^{11}$ Furthermore, abductor muscle strength deficit has been linked to knee $\mathrm{OA},{ }^{5} 12$ patellofemoral pain syndrome $\mathrm{e}^{13}$ and chronic lower back pain. ${ }^{14}$ Especially for the elderly population, loss of abduction function can compromise balance and increase the risk of falls. ${ }^{15}$ Specifically for THA, abductor muscle function has been shown to be directly associated with physical function ${ }^{5}$ and important in limiting limping. ${ }^{16}$ Overall, conservation of the abduction muscle strength is important not only for an optimal outcome of THA but also to prevent pain because of other orthopaedic conditions linked to abductor strength deficits.

Many studies have tried to explore and quantify a potential abductor muscle strength deficit after THA as well as identify possible causes and treatment options. ${ }^{4517}$ Furthermore, surgical approaches avoiding any damage to the abductor mechanism have been established ${ }^{18}$ and rehabilitation programmes have been developed to prevent or reduce this strength deficit. ${ }^{17} 1920$ However, results reported in the literature are controversial, and the factors influencing abductor muscle strength deficit after THA are poorly understood.

The aim of this protocol study was to present an objective and transparent methodology to conduct a systematic review and meta-analysis aimed to increase knowledge regarding the magnitude of abductor muscle strength deficits after THA and to depict, as well as to provide understanding of the associations to external between factors including patient characteristics, surgical methods and rehabilitation programmes and abductor muscle strength deficit after THA and study characteristics

\section{METHODS AND ANALYSES}

This protocol is reported according to the Preferred Reporting Items for Systematic Review and Meta-Analysis Protocols (PRISMA-P) guideline. ${ }^{21}$ The initial preliminary search was conducted on 5 May 2019. The study was submitted for registration in PROSPERO on 2 October 2019 and registered on 26 February 2020. The anticipated completion date is 30 June 2020. The research question was formulated according to the Population, Intervention, Comparison, Outcome, Study design tool (table 1$){ }^{22}$

\section{Eligibility criteria}

Inclusion criteria

Human-based clinical studies reporting on abductor muscle strength after THA performed for OA of the hip will be considered for inclusion. No restriction will be placed on study design, publication date, operative approach, prosthesis design, age and sex of the patients or severity of OA
Table 1 The Population, Intervention, Comparison, Outcome, Study design process

\begin{tabular}{|c|c|}
\hline Item & Specification \\
\hline $\begin{array}{l}\text { Population, or participants } \\
\text { and conditions of interest }\end{array}$ & $\begin{array}{l}\text { Patients with OA of the hip } \\
\text { (any age, any gender and any } \\
\text { severity) }\end{array}$ \\
\hline Interventions or exposures & Total hip arthroplasty \\
\hline $\begin{array}{l}\text { Comparisons or control } \\
\text { groups }\end{array}$ & $\begin{array}{l}\text { For comparison between } \\
\text { limps of the same subject: } \\
\text { asymptomatic contralateral } \\
\text { hip } \\
\text { For comparison between } \\
\text { patients and heathy } \\
\text { individuals: asymptomatic } \\
\text { control subjects }\end{array}$ \\
\hline Outcomes of interest & $\begin{array}{l}\text { Muscle strength of hip } \\
\text { abductors }\end{array}$ \\
\hline Study designs & $\begin{array}{l}\text { Any study design, only } \\
\text { published studies, no } \\
\text { conference abstracts }\end{array}$ \\
\hline
\end{tabular}

$\mathrm{OA}$, osteoarthritis.

\section{Exclusion Criteria}

Studies published in a language other than English or German as well as studies not reporting absolute muscle strength values or torque ratios will be excluded. Studies reporting on hip abductor strength measured manually or at an abduction angle other than $0^{\circ}$ will not be considered for this review.

\section{Methodological considerations}

Studies reporting on hip abductor strength measured manually (with a hand-held manometer or without a manometer) will not be considered because the results are not reliable and not directly comparable with studies using electronic dynamometers. In addition, studies reporting on isometric abductor muscle strength at an abduction angle other than $0^{\circ}$ will not be included because torque measurement at other angles cannot be compared with those conducted in $0^{\circ}$ abduction and does not reflect the relevant muscle strength during walking and standing.

\section{Information sources and search strategy}

Text words (synonyms and word variations) and databasespecific subject headings for hip OA, total hip replacement and postoperative performance will be used. We will search the electronic databases Embase via embase. com, Medline ALL via Ovid, and the Cochrane Central Register of Controlled Trials. No language or date restrictions will be applied. All retrieved references will be exported to Endnote V.X9 and deduplicated. To identify possible additional studies that will escape our electronic database searches, the bibliographic references of all included articles as well as the citations of those that are indexed in Scopus or the Web of Science will be screened. An initial search took place on 5 May 2019. The detailed 


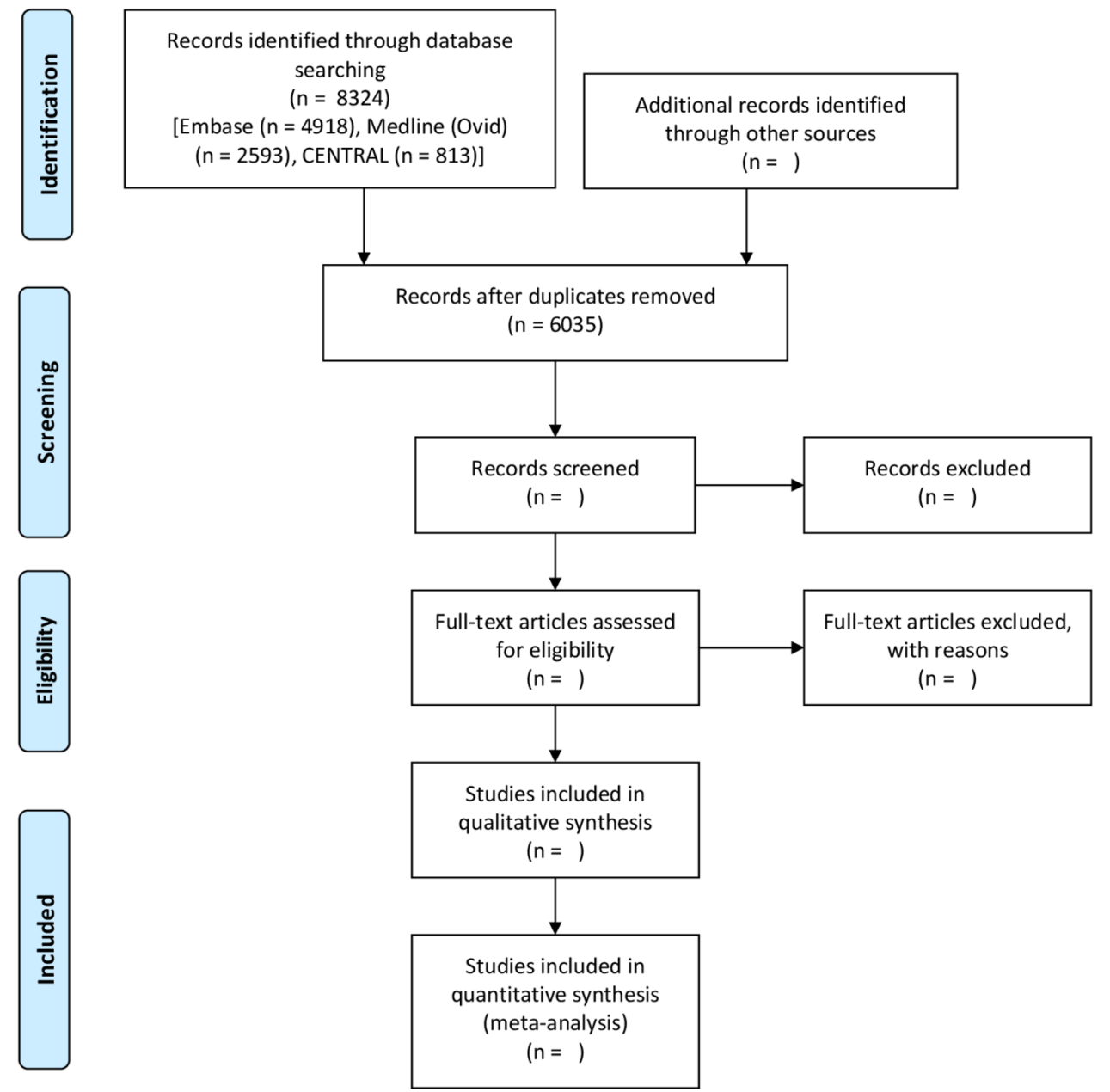

Figure 1 Preferred Reporting Items for Systematic Reviews and Meta-Analyses flow diagram. CENTRAL, Cochrane Central Register of Controlled Trials.

search strategy can be found in the online supplementary file a. The search strategy will be presented in form of a PRISMA diagram (figure 1). ${ }^{23}$

\section{Study records: data management, selection process and data} collection process

Two reviewers (PI and PK) will independently screen the references based on their titles and abstracts to identify studies that potentially meet the inclusion criteria. All potentially relevant references will be retrieved in full text and independently assessed by two reviewers (PI and PK). Any disagreements over eligibility will be resolved by consensus. Where necessary, a third review author (AM) will make a final judgement. Data from the full texts will be extracted and entered into a standardised form. The information to be extracted can be found in table 2 .

\section{Outcomes and prioritisation}

The main outcomes include:

1. Absolute values of hip abductor torque in patients after THA, or in asymptomatic control groups.

2. Torque ratio (operated/contralateral hip) of hip abductors in patients after unilateral THA.
3. Change in hip abductor torque/hip abductor torque ratio from baseline to the last available follow-up.

4. Differences in hip abductor torque/torque ratios between patients after THA and healthy control groups.

The secondary outcomes include:

1. Surgical approaches/methods influencing the abductor muscle strength deficits after THA.

2. Patient characteristics influencing the abductor muscle strength deficits after THA.

3. Rehabilitation programmes influencing the abductor muscle strength deficits after THA.

4. Study characteristics influencing the results.

\section{Risk of bias in individual studies}

The risk-of-bias assessment will be performed with a modified version of the Newcastle-Ottawa scale $\left(\mathrm{NOS}^{24}\right.$; online supplementary file b) and conducted independently by two reviewers (PI and PK). According to the modified NOS, each study will be valued with 1-6 stars where higher scores indicate higher level of quality. No separate tool will be used to assess the risk of bias of randomised controlled trials (RCTs), since we do not extract estimates 


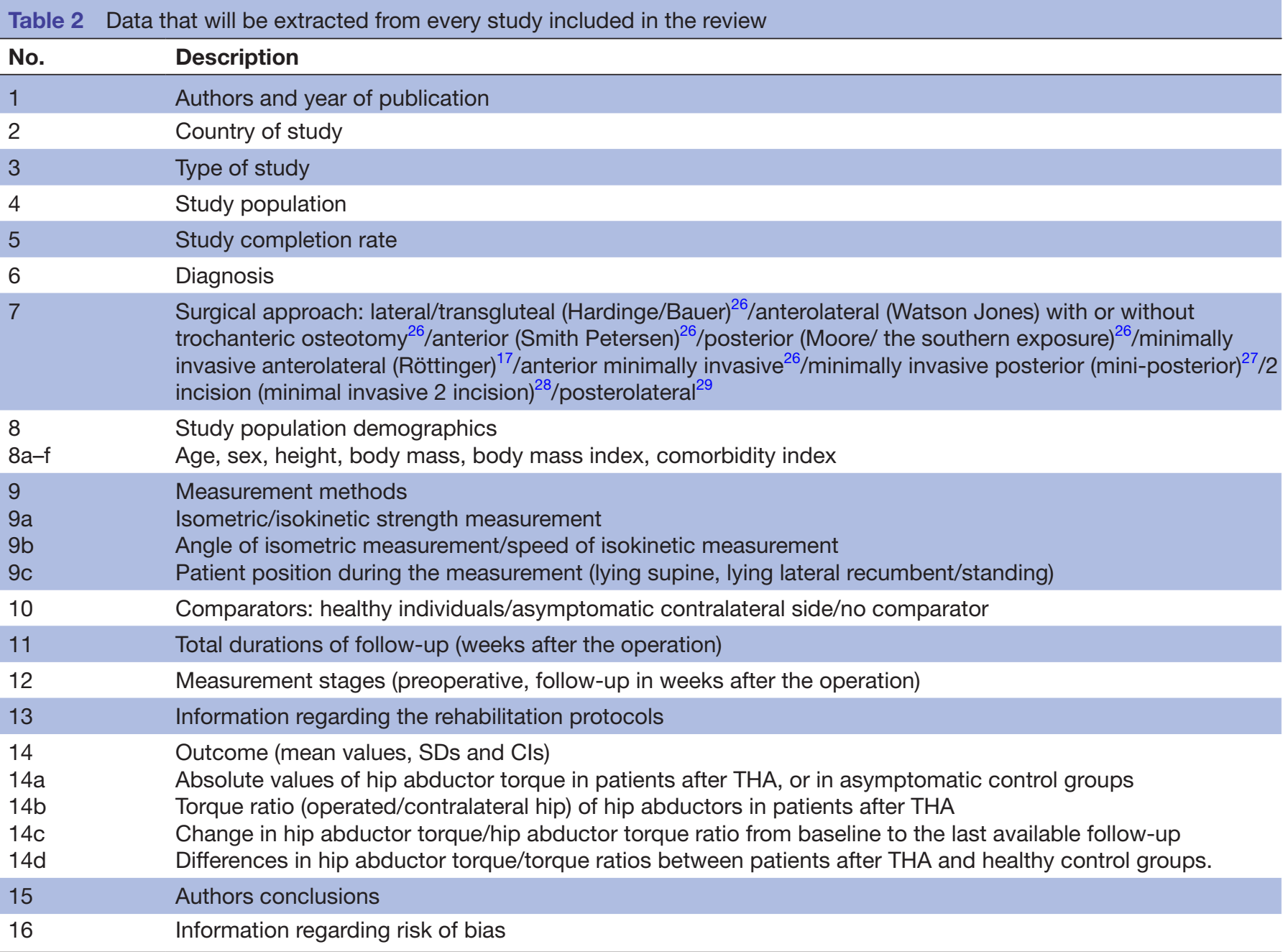

THA, total hip arthroplasty.

of treatment differences from RCTs but use them as a source for observational data.

\section{Data synthesis}

For any of the main outcomes, we will extract any information on the location (mean, median, etc) and any information on the population variation (SD, IQR, percentile) or on the precision of the location measure (standard errors, CIs, $p$ values, sample size). If this information is available for several time points, the data will be extracted for all time points.

If results are given for specific patient subgroups, these results will be extracted together with the characteristics of the subgroup. The same applies for comparisons beyond those reflected by the main outcomes. In case that outcomes are not reported directly but indirect information is available on side-specific or time point-specific results, the available information will be transformed accordingly.

If several studies using the same type of measurement (isokinetic or isometric) at the same time period after THA and with the same comparator (asymptomatic contralateral side or group of asymptomatic control subjects) are available, we will pool the results for a meta-analysis.

All results will be presented in tabular format and forest plots. Whenever outcomes are not reported directly but only indirect information is available on side-specific or time point-specific results, the available information will be transformed accordingly.

Metaregression and subgroup-specific meta analyses will be used to investigate the influence of time since THA and type of measurement (isokinetic or isometric) on the different outcomes. In case of sufficient information, these analyses will be extended to include characteristics such as age, sex, surgical approach or rehabilitation programme.

\section{Metabias(es)}

To explore potential hints to publication bias or selective reporting, we will investigate the influence of all available study characteristics on the various outcomes.

\section{Confidence in cumulative evidence}

The strength of the body of evidence will be assessed with the Grading of Recommendations Assessment, 
Development and Evaluation system (GRADE).$^{25}$ GRADE is a method of assessing the certainty in evidence classifying it into one of the four categories: high, moderate, low and very low. ${ }^{25}$

\section{ETHICS AND DISSEMINATION}

This study is a protocol for a systematic review and metaanalysis. No human participants will be recruited. No ethics approval is needed. The results will be disseminated through peer-reviewed publications and conference presentations. All data relevant to the study are included in the article or uploaded as supplementary information.

\section{Author affiliations}

${ }^{1}$ Department of Orthopaedics and Traumatology, University Hospital of Basel, Basel, Switzerland

${ }^{2}$ Department of Clinical Research, University of Basel, Basel, Switzerland

${ }^{3}$ Department of Orthopaedic Surgery and Traumatology, Kantonsspital Baselland,

Bruderholz, Basel-Landschaft, Switzerland

${ }^{4}$ University Medical Library, University of Basel, Basel, Switzerland

${ }^{5}$ Department of Biomedical Engineering, University of Basel, Basel, Switzerland

\section{Twitter Peter Kvarda @Kvarda}

Contributors $\mathrm{PI}, \mathrm{PK}$ and $\mathrm{AM}$ conceived this systematic review and meta-analysis. PI registered the protocol in PROSPERO. CA-H reviewed the protocol and was responsible for the search strategy. WV reviewed the protocol and was responsible for the strategy of data synthesis. All authors provided critical feedback, have read and approved the final manuscript.

Funding This study was funded by the Department of Orthopaedics of the University Hospital Basel and the the Foundation for Funding Science and Education at the Department of Surgery at the University of Basel.

Competing interests None declared.

Patient and public involvement Patients and/or the public were not involved in the design, or conduct, or reporting, or dissemination plans of this research.

Patient consent for publication Not required.

Provenance and peer review Not commissioned; externally peer reviewed.

Open access This is an open access article distributed in accordance with the Creative Commons Attribution Non Commercial (CC BY-NC 4.0) license, which permits others to distribute, remix, adapt, build upon this work non-commercially, and license their derivative works on different terms, provided the original work is properly cited, appropriate credit is given, any changes made indicated, and the use is non-commercial. See: http://creativecommons.org/licenses/by-nc/4.0/.

\section{ORCID iDs}

Petros Ismailidis http://orcid.org/0000-0003-1551-7902

Peter Kvarda http://orcid.org/0000-0002-1623-4712

Christian Appenzeller-Herzog http://orcid.org/0000-0001-7430-294X

\section{REFERENCES}

1 Gademan MGJ, Hofstede SN, Vliet Vlieland TPM, et al. Indication criteria for total hip or knee arthroplasty in osteoarthritis: a state-ofthe-science overview. BMC Musculoskelet Disord 2016;17:463.

2 Lau RL, Gandhi R, Mahomed S, et al. Patient satisfaction after total knee and hip arthroplasty. Clin Geriatr Med 2012;28:349-65.

3 Judd DL, Dennis DA, Thomas AC, et al. Muscle strength and functional recovery during the first year after THA. Clin Orthop Relat Res 2014;472:654-64.
4 Rasch A, Dalén N, Berg HE. Muscle strength, gait, and balance in 20 patients with hip osteoarthritis followed for 2 years after THA. Acta Orthop 2010;81:183-8.

5 Cinnamon CC, Longworth JA, Brunner JH, et al. Static and dynamic abductor function are both associated with physical function 1 to 5 years after total hip arthroplasty. Clin Biomech 2019;67:127-33.

6 Klausmeier V, Lugade V, Jewett BA, et al. Is there faster recovery with an anterior or anterolateral THA? A pilot study. Clin Orthop Relat Res 2010;468:533-41.

7 Shih $\mathrm{CH}$, Du YK, Lin YH, et al. Muscular recovery around the hip joint after total hip arthroplasty. Clin Orthop Relat Res 1994;302:115???120-20.

8 Neumann DA. Kinesiology of the hip: a focus on muscular actions. $J$ Orthop Sports Phys Ther 2010;40:82-94.

9 Flack NAMS, Nicholson HD, Woodley SJ. A review of the anatomy of the hip abductor muscles, gluteus medius, gluteus minimus, and tensor fascia lata. Clin Anat 2012;25:697-708.

10 Ebert JR, Edwards PK, Fick DP, et al. A systematic review of rehabilitation exercises to progressively load the gluteus Medius. $J$ Sport Rehabil 2017;26:418-36.

11 Gandbhir VN, Rayi A. Trendelenburg gait. StatPearls. Treasure Island FL: StatPearls Publishing LLC, 2019.

12 Chang A, Hayes K, Dunlop D, et al. Hip abduction moment and protection against medial tibiofemoral osteoarthritis progression. Arthritis Rheum 2005;52:3515-9.

13 Piva SR, Goodnite EA, Childs JD. Strength around the hip and flexibility of soft tissues in individuals with and without patellofemoral pain syndrome. J Orthop Sports Phys Ther 2005;35:793-801.

14 Cooper NA, Scavo KM, Strickland KJ, et al. Prevalence of gluteus medius weakness in people with chronic low back pain compared to healthy controls. Eur Spine J 2016;25:1258-65.

15 Inacio M, Ryan AS, Bair W-N, et al. Gluteal muscle composition differentiates fallers from non-fallers in community dwelling older adults. BMC Geriatr 2014;14:37.

16 Horstmann T, Listringhaus R, Brauner T, et al. Minimizing preoperative and postoperative limping in patients after total hip arthroplasty: relevance of hip muscle strength and endurance. Am J Phys Med Rehabil 2013;92:1060-9.

17 Bertin KC, Röttinger H. Anterolateral mini-incision hip replacement surgery: a modified Watson-Jones approach. Clin Orthop Relat Res 2004;429:248-55.

18 Onyemaechi N, Anyanwu E, Obikili E, et al. Anatomical basis for surgical approaches to the hip. Ann Med Health Sci Res 2014;4:487-94.

19 Di Monaco M, Vallero F, Tappero R, et al. Rehabilitation after total hip arthroplasty: a systematic review of controlled trials on physical exercise programs. Eur J Phys Rehabil Med 2009;45:303-17.

20 Post ZD, Orozco F, Diaz-Ledezma C, et al. Direct anterior approach for total hip arthroplasty: indications, technique, and results. J Am Acad Orthop Surg 2014;22:595-603.

21 Shamseer L, Moher D, Clarke M, et al. Preferred reporting items for systematic review and meta-analysis protocols (PRISMA-P) 2015: elaboration and explanation. BMJ 2015;350:g7647.

22 Methley AM, Campbell S, Chew-Graham C, et al. PICO, PICOS and spider: a comparison study of specificity and sensitivity in three search tools for qualitative systematic reviews. BMC Health Serv Res 2014;14:579.

23 Moher D, Liberati A, Tetzlaff J, et al. Preferred reporting items for systematic reviews and meta-analyses: the PRISMA statement. PLoS Med 2009;6:e1000097.

24 Wells G, Shea B, O'Connell D, et al. The Newcastle-Ottawa scale (NOS) for assessing the quality of case-control studies in metaanalyses. Eur J Epidemiol 2011;25:603-5.

25 Guyatt GH, Oxman AD, Vist GE, et al. Grade: an emerging consensus on rating quality of evidence and strength of recommendations. $B M J$ 2008;336:924-6.

26 Hoppenfeld S, Pd B, Buckley R. Surgical exposures in orthopaedics : the anatomic approach, 2017.

27 Della Valle CJ, Dittle E, Moric M, et al. A prospective randomized tria of mini-incision posterior and two-incision total hip arthroplasty. Clin Orthop Relat Res 2010;468:3348-54.

28 Berger RA. Total hip arthroplasty using the minimally invasive twoincision approach. Clin Orthop Relat Res 2003;417:232-41.

29 Roberts JM, Fu FH, McClain EJ, et al. A comparison of the posterolateral and anterolateral approaches to total hip arthroplasty. Clin Orthop Relat Res 1984;187:205-10. 